\title{
MULTIPLE CONTINGENCY ANALYSIS FOR OPTIMAL PLACEMENT AND ESTIMATE THE VALUE OF SVC FOR POWER LOSS REDUCTION EMPLOYING GENETIC ALGORITHM
}

\author{
Mohammed Shuaib Iqbal \\ PG Scholar, Department of Electrical Engineering, \\ University Visvesvaraya College of Engineering, Bengaluru, India. \\ Sujatha B.C \\ Associate Professor, Department of Electrical Engineering, \\ University Visvesvaraya College of Engineering, Bengaluru, India.
}

\begin{abstract}
The development of FACTs technology has been a great help in enhancing the function of power systems as it minimizes the power system instability problem, minimize losses and voltage profile. Due to high capitals involved with Flexible AC transmission systems (FACTs) devices, proper planning in the early phase of commissioning is essential so as to achieve maximum feasible use of them. Positioning FACTs devices in proper place can assist the objective of enhancing voltage levels and minimizing losses in the structure. In this paper, Genetic Algorithm (GA) is used to discover the ideal place of Static VAR Compensator (SVC) for the increase in load condition and loss of generation. An appreciable reduction in active power loss and improvement in voltage profile are observed. The MATLAB program with MATPOWER is used to demonstrate the procedure on IEEE 30 bus test system.
\end{abstract}

Keywords: Static VAR Compensator (SVC), Genetic Algorithm (GA), Contingency Analysis

Cite this Article: Mohammed Shuaib Iqbal and Sujatha B.C, Multiple Contingency Analysis for Optimal Placement and Estimate the Value of SVC for Power Loss Reduction Employing Genetic Algorithm, International Journal of Electrical Engineering \& Technology, 10(4), 2019, pp. 60-69.

http://iaeme.com/Home/issue/IJEET?Volume=10\&Issue $=4$ 


\section{INTRODUCTION}

Power system structures are complex systems that are nonlinear, non-stationary, and disposed to disruption and faults. Strengthening of a power system can be achieved by enhancing voltage profiles, increasing the transmission size, loss reduction and others.

Due to increase in inhabitants demands the existing transmission structures to be upgraded to transfer more power. Therefore, managing the power flow in the network is an important problem in designing and functioning of the power system. By using FACTs devices, system can be enhanced for regulating the power flow and size of transmission line [1].

Classification of FACTs devices are based on power electronic converters known for its efficiency to control several variables of power structure in electric transmission circuits for stable power flow as well as dynamic stability control. In FACTs devices Static VAR Compensator (SVC) is employed because of its lower cost in contrast with STATCOM.

The main objective of utilizing a Static VAR compensator in a power system is to enhance the power transmission efficiency, with a given transmission structure, from the generators to the loads. The voltage control is influenced alternately by SVC which cannot generate or absorb true power in power transmission structure. In order to have desired power flow under feasible system disruption and contingencies, the output reactive power of compensator is modified to control the voltage at given terminals of transmission structure. For mitigating power structure losses, SVC is placed at ideal position. In [2], GA is utilized for ideal placement of SVC for mitigating power loss and reducing size of SVC.

In this paper GA is used for finding an ideal position and value of SVC to mitigate true power loss, and enhance voltage profile and to adjust the value of SVC. GA is used for figuring out an optimized problem for the position of SVC. To demonstrate the efficiency of the technique IEEE 30 bus structure is employed. Typically, works in this area reduce the computational burden by either decreasing the time required to evaluate contingency [9-12] or by reducing the number of cases to be evaluated.

\subsection{Need for Good Voltage Profiles}

- Proper voltage profile is very crucial in power system to maintain power grid in a stable and reliable mode. It is very important in power system that maintaining voltages within specified at each and every point of time because load on the grid is always varying.

- It is first and foremost criteria in power system to maintain proper supply voltage to avoid damage of Electrical equipment because they are sensitive to voltage fluctuations.

- Power system network is a interconnected grid with different geographical regions, various sizes of grids, different connection rules, dissimilar characteristics, and therefore it is very important to maintain proper voltage profile of the grid.

- By maintaining optimal voltage levels in the system, power consumption can be reduced from voltage dependent loads and saves cost of generation.

- Motor and Transformers draw higher currents and leads to over - heating consequently high power consumption due to under voltages in the power system[7].

\section{STATIC VAR COMPENSATOR (SVC)}

The SVC is a static VAR generator/load whose output is arranged to switch capacitive or inductive current so as to vary power system variable [3, 4]. Conventionally, the terminal bus voltage is the power system control variable. SVC's have two conventional forms. One form solely of a Thyristor-Controlled Reactor (TCR) and the other solely of a Thyristor-Switched 
Capacitor (TSC). In order to behave SVC as a fixed capacitor or an inductor unit, susceptance limit has been varied from minimum or maximum.

Multiple Contingency Analysis for optimal placement and estimate the value of SVC for power loss reduction employing Genetic Algorithm.

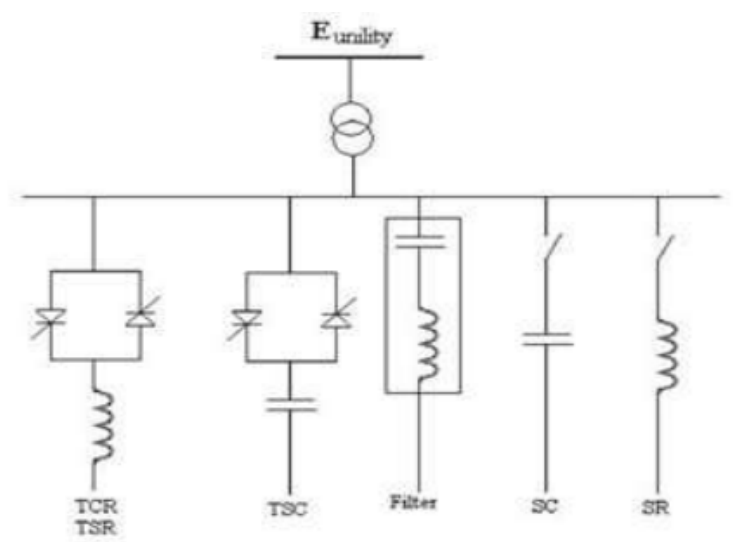

Figure 1. Schematic Diagram of SVC connected to an electric utility

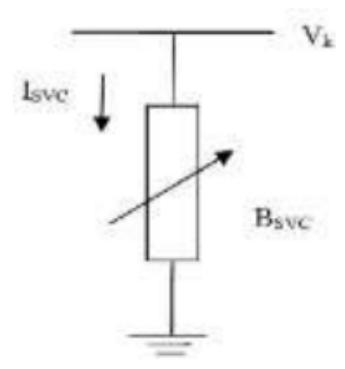

Figure 2 illustrates the current injected model by SVC.

Reactive power injected into the bus-bar is given by the equation (1) below:

$Q S V C=B S V C * \mathrm{~V} 2$

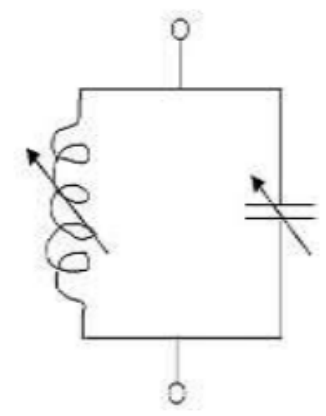

Figure 3 Ideal static reactive compensator

\section{PROBLEM FORMULATION}

\section{A. Reduction of true power loss}

$\mathrm{F} 1(\mathrm{u}, \mathrm{v})$ of the objective function is specified as the true power loss (PL):

$$
P L=\sum_{k=1}^{N L}\left(g_{k}\left[V_{m}^{2}+V_{n}^{2}-2 V_{m} V_{n} \cos \left(\delta_{m}-\delta_{n}\right)\right]\right)
$$


Where, NL and gk depict total transmission lines and line conductance; the end buses magnitude and phase angles of the voltages are $\mathrm{Vm}, \delta \mathrm{m}$ and $\mathrm{Vn}, \delta$ n respectively.

\section{B. Reduction of value of SVC}

F2 (SVC value) of the objective function is for reduction of SVC value.

F2 $($ SVC value $)=$ Rating of SVC in p.u.

\section{Objective function}

The global optimized problem can be acquired by uniting above two objectives mentioned which is:

$$
\mathrm{fF}(\mathrm{u}, \mathrm{v})=\mathrm{F} 1(\mathrm{u}, \mathrm{v})+\mathrm{F} 2(\mathrm{SVC} \text { size })
$$

Now, by reducing the objective function $\mathrm{fF}(\mathrm{u}, \mathrm{v})$ the optimization can be carried out, subject to different equality and inequality constraints.

\section{Equality Constraints:}

The equations of conventional power flow rate equality constraints are as follows:

$$
\mathrm{PGm}-\mathrm{PDm}-\mathrm{PL}=0
$$

$$
\begin{gathered}
\text { For } \mathrm{m}=1 \ldots \ldots \ldots \ldots \ldots \ldots \ldots \\
\mathrm{QGm}-\mathrm{QDm}-\mathrm{QL}=0
\end{gathered}
$$

For $\mathrm{m}=1$ NB

Where, NB represents bus number. $\mathrm{P}_{\mathrm{Gm}}$ and $\mathrm{Q}_{\mathrm{Gm}}$ are true and reactive powers of generator at bus $\mathrm{m}$ and $\mathrm{n} ; \mathrm{P}_{\mathrm{Dm}}$ and $\mathrm{Q}_{\mathrm{Dm}}$ are the load true and reactive power at bus $\mathrm{m}$ and $\mathrm{n}$ respectively.

\section{Inequality Constraints}

Generator reactive power for lower and upper limits in the inequality constraints can be written as:

$$
\begin{gathered}
\mathrm{Q}_{\mathrm{Gm}}{ }^{\mathrm{min}} \leq \mathrm{Q}_{\mathrm{Gm}} \leq \mathrm{Q}_{\mathrm{Gm}}{ }^{\max } \\
\mathrm{V}_{\mathrm{m}}{ }^{\text {min }} \leq \mathrm{V}_{\mathrm{m}} \leq \mathrm{V}_{\mathrm{m}}{ }^{\text {max }} \\
\mathrm{m}=1,2,3 \ldots \ldots \ldots \ldots \mathrm{NG}
\end{gathered}
$$

\section{GENETIC ALGORITHM}

\section{A. Summary of GA}

GA is the approach of natural selection and genetics for global search optimization. The objective function does not need any former information and concurrently it finds various possible solutions. It develops proper characteristic solutions because it doesn't depend on initial parameters. The feasible solutions of the optimized problem of the initial population of GA is set off with the random formation.. The fitness function is estimated by the value of every individual of the objective function. Using genetic operators (selection, crossover and mutation) more fit individuals obtained are distinguished as new population till the convergence criteria has met or allocated maximum number of generations is attained. Ultimately, the individuals in the population are set to be almost uniform as the population steadies[7]. 


\section{B. Implementation of GA}

\section{Initialization}

Every individual in the population indicates a candidate solution. More than one decision parameter includes in a problem, every parameter is indicated by a string. Two strings are indicated for an individual in this work, where, the position of the devices is associated with first string, and the device value indicates the second string.

The specification of SVC in this paper is depicted with some variables, particularly the position and value of the equipments. A string that relies upon SVC variable indicates every individual used for optimization. The position of SVC depicts first value in every string. The value of the device depicts rest of the values in the string.

In order to place the SVC i.e. NB, NR initialize the populations from different possible positions. The outcome of the new generation can be obtained from the old generation.

Multiple Contingency Analysis for optimal placement and estimate the value of SVC for power loss reduction employing Genetic Algorithm.

\section{Selection strategy}

The selection technique among individuals are managed based on their fitness function which depicts natural selection build in biological evolutions. In order to get next generation poor operating individuals are eliminated and better operating individuals have greater chances. The suggested number of selection operators are in [5]. The most commonly used are tournament selection and roulette wheel selection. In this paper tournament wheel selection is used.

\section{Crossover operation}

A crossover interchanges data from selected parents is regarded as merging operator. There are two types of crossover:

a. Single point crossover.

b. Multiple point crossover.

In this paper, double point Crossover is used.

\section{Mutation}

Mutation is used for altering one or more bit position of the selected string for low mutation probability.

Mutation probability $=0.01$ is considered in this work.

The offspring is generated from all above mentioned operators. The objective function (4) is evaluated to create a new generation of all of the offspring and some of the individual best among them. The process is used to relate average fitness of a new generation and best value of the objective function. 




Figure 4 Flowchart for GA Implementation

\section{RESULTS}

GA is evaluated to find ideal position and estimate the value of SVC in IEEE 30 bus system [6]. For contingency as well as base load conditions the system is tested. It consists of 6 generators with a generation capacity of $192.06 \mathrm{MW}$ and 105.08 MVAR, 41 lines and real and reactive power load of 189.2 MW and 107.20 MVAR and SVC with value of 100 MVAR.

The ideal settings of the GA control variables are given below:

The ideal settings of the GA control variables are given below:

Size of population: 20

Total number of generations: 50

Probability of mutation: 0.05

Crossover probability: 0.9

Elitism: 0.2

Voltage profile and power loss are examined for different cases for increase in load and loss of generation at bus 13 are shown in Table I. By examining this figures below, it can be concluded that the position of SVC enhances the voltage stability and decreases the power loss. 
Mohammed Shuaib Iqbal and Sujatha B.C

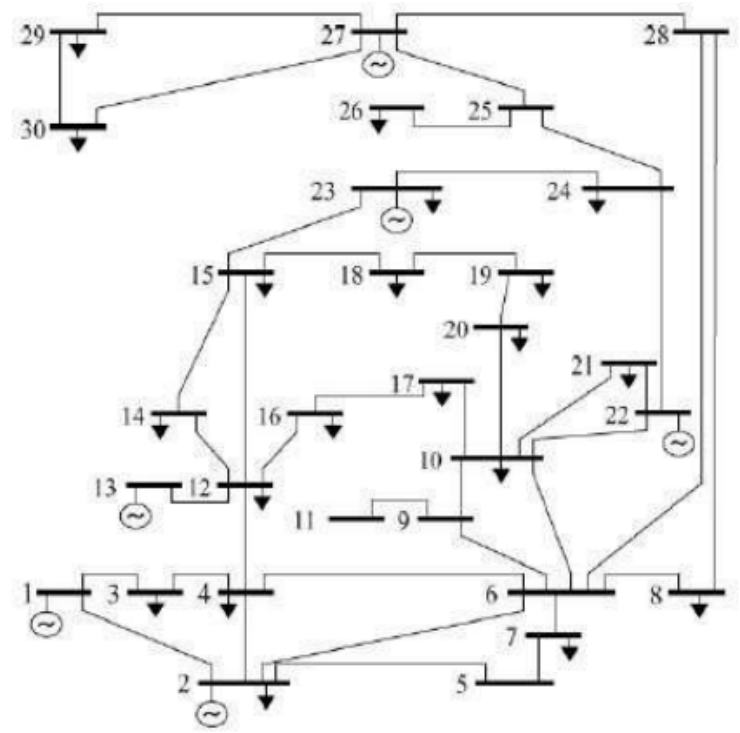

Figure 5 IEEE 30 bus test system.

Case1: Base case without Contingency

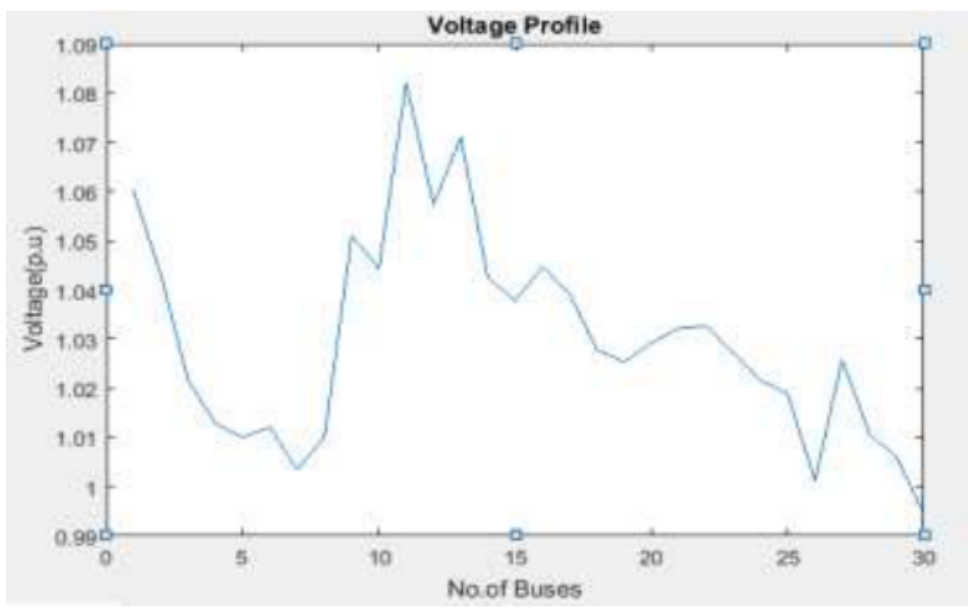

Figure 6 Voltage profile for base case

Case2: $20 \%$ increase in loading with and without SVC

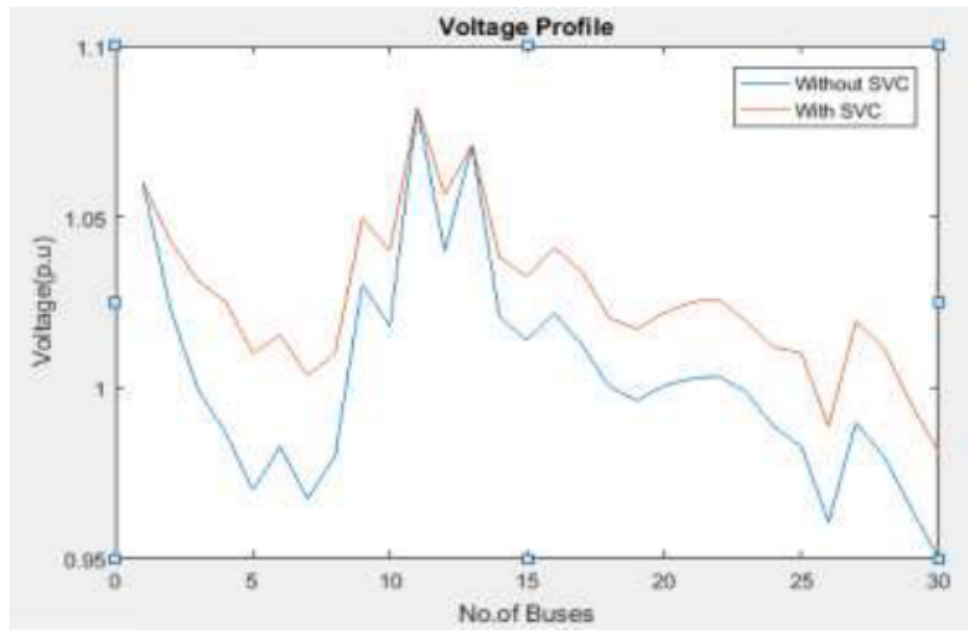

Figure 7: Voltage profile for $20 \%$ enhanced load (with \& without SVC). 
Multiple Contingency Analysis for optimal placement and estimate the value of SVC for power loss reduction employing Genetic Algorithm.

Case3: $50 \%$ increase in loading and removal of generator with and without SVC

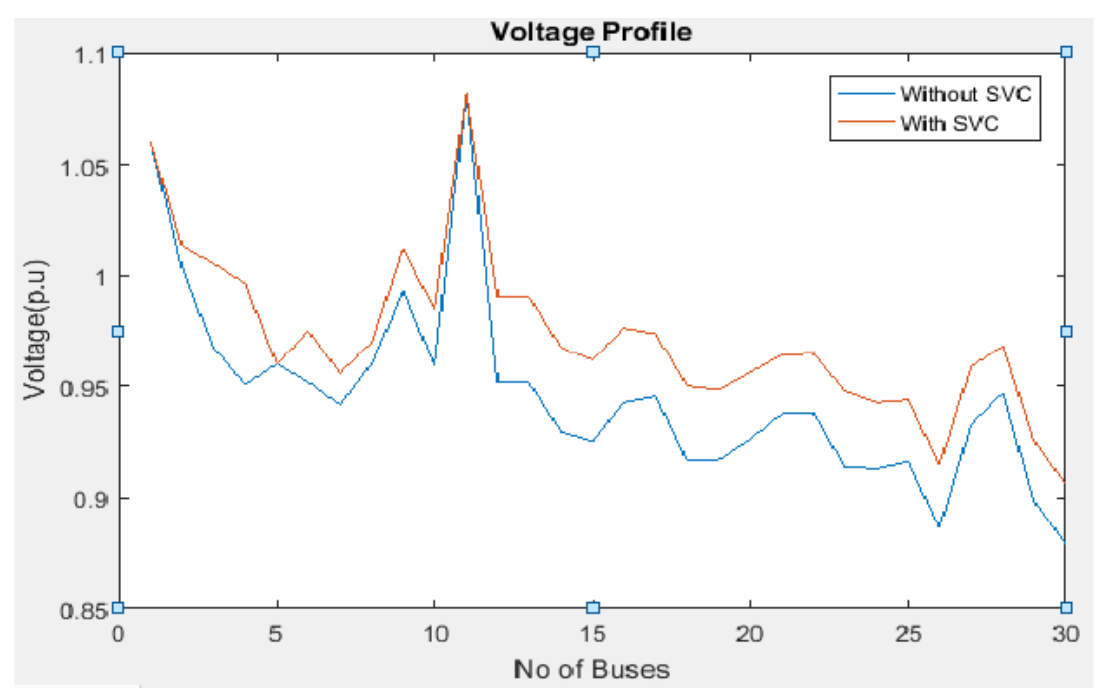

Figure 8 Voltage profile for $50 \%$ enhanced load \& removal of of generation at bus 13(with \& without SVC).

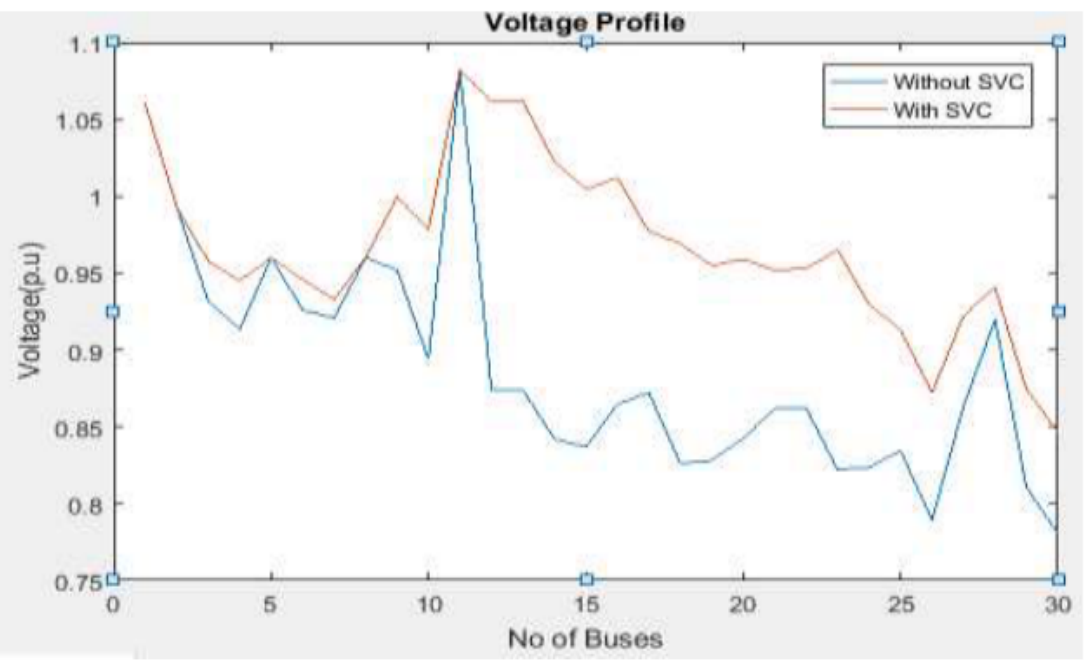

Figure 9 Voltage profile for $100 \%$ enhanced load \& removal generation at bus 13 (with \& without SVC).

\section{Losses with optimal location and size of SVC}

\begin{tabular}{|c|c|c|c|c|c|c|}
\hline \multirow{3}{*}{\begin{tabular}{|l} 
Base Case \\
Without \\
Contingency
\end{tabular}} & \multicolumn{2}{|r|}{ Case2 } & \multicolumn{2}{|r|}{ Case3 } & \multicolumn{2}{|r|}{ Case4 } \\
\hline & Without & With SVC for & Without & With SVC for & Without & With SVC for \\
\hline & $\begin{array}{l}\text { SVC for } \\
20 \% \\
\text { increase in } \\
\text { loading }\end{array}$ & $\begin{array}{l}20 \% \text { increase in } \\
\text { loading }\end{array}$ & $\begin{array}{l}\text { SVC for } \\
50 \% \\
\text { increase in } \\
\text { loading and } \\
\text { removal of } \\
\text { generator }\end{array}$ & $\begin{array}{l}50 \% \text { increase in } \\
\text { loading and } \\
\text { removal of } \\
\text { generator } \\
\text { location and } \\
\text { size }\end{array}$ & $\begin{array}{l}\text { SVC for } \\
100 \% \\
\text { increase in } \\
\text { loading and } \\
\text { removal of } \\
\text { generator }\end{array}$ & $\begin{array}{l}100 \% \text { increase in } \\
\text { loading and } \\
\text { removal of } \\
\text { generator }\end{array}$ \\
\hline \multirow[b]{2}{*}{ 17.599(MW) } & \multirow[b]{2}{*}{ 27.298(MW) } & \begin{tabular}{|l|l|} 
Bus4 & 63.747 (MVAR) \\
\end{tabular} & \multirow[b]{2}{*}{ 47.824(MW) } & \begin{tabular}{|l|l|} 
Bus4 & 95.389(MVAR \\
\end{tabular} & \multirow[b]{2}{*}{ 99.584(MW) } & \begin{tabular}{|l|l|} 
Bus12 & 99.842(MVAR) \\
\end{tabular} \\
\hline & & 26.607(MW) & & 45.562(MW) & & 93.762(MW) \\
\hline
\end{tabular}


Table 1 Voltage profile with \& without SVC for different cases:

\begin{tabular}{|c|c|c|c|c|c|c|c|}
\hline \multirow{2}{*}{\multicolumn{2}{|c|}{\begin{tabular}{|c|} 
Base Case (Casel) \\
$\begin{array}{c}\text { Without Contingency } \\
\text { in (p.u) }\end{array}$
\end{tabular}}} & \multicolumn{2}{|c|}{ Case2 } & \multicolumn{2}{|c|}{ Case 3} & \multicolumn{2}{|c|}{ Case4 } \\
\hline & & $\begin{array}{c}\text { Without SVd } \\
\text { in (p.u) }\end{array}$ & $\begin{array}{c}\text { With SVC } \\
\text { in (p.u) }\end{array}$ & $\begin{array}{c}\text { Without SVC } \\
\text { in (p.u) }\end{array}$ & $\begin{array}{r}\text { With SVC } \\
\text { in (p.u) }\end{array}$ & $\begin{array}{c}\text { Without SVC } \\
\text { in (p.u) }\end{array}$ & $\begin{array}{c}\text { With SVC } \\
\text { in (p.u) }\end{array}$ \\
\hline Bus & Voltage & Voltage & Voltage & Voltage & Voltage & Voltage & Voltage \\
\hline No. & Mag. & Mag. & Mag. & Mag. & Mag. & Mag. & Mag. \\
\hline 1 & 1.060 & 1.060 & 1.060 & 1.060 & 1.060 & 1.060 & 1.060 \\
\hline 2 & 1.043 & 1.023 & 1.033 & 1.003 & 1.013 & 0.993 & 0.993 \\
\hline 3 & 1.022 & 0.999 & 1.030 & 0.968 & 1.005 & 0.932 & 0.958 \\
\hline 4 & 1.013 & 0.987 & 1.025 & 0.950 & 0.996 & 0.913 & 0.945 \\
\hline 5 & 1.010 & 0.970 & 0.990 & 0.960 & 0.960 & 0.960 & 0.960 \\
\hline 6 & 1.012 & 0.983 & 1.012 & 0.952 & 0.975 & 0.926 & 0.946 \\
\hline 7 & 1.003 & 0.967 & 0.993 & 0.942 & 0.956 & 0.921 & 0.933 \\
\hline 8 & 1.010 & 0.980 & 1.010 & 0.960 & 0.970 & 0.960 & 0.960 \\
\hline 9 & 1.051 & 1.030 & 1.047 & 0.993 & 1.011 & 0.952 & 1.000 \\
\hline 10 & 1.044 & 1.018 & 1.037 & 0.959 & 0.985 & 0.894 & 0.978 \\
\hline 11 & 1.082 & 1.082 & 1.082 & 1.082 & 1.082 & 1.082 & 1.082 \\
\hline 12 & 1.057 & 1.040 & 1.056 & 0.951 & 0.990 & 0.874 & 1.062 \\
\hline 13 & 1.071 & 1.071 & 1.071 & 0.951 & 0.990 & 0.874 & 1.062 \\
\hline 14 & 1.042 & 1.021 & 1.038 & 0.930 & 0.967 & 0.842 & 1.022 \\
\hline 15 & 1.038 & 1.014 & 1.031 & 0.925 & 0.961 & 0.837 & 1.005 \\
\hline 16 & 1.045 & 1.022 & 1.039 & 0.943 & 0.976 & 0.865 & 1.012 \\
\hline 17 & 1.039 & 1.013 & 1.031 & 0.946 & 0.973 & 0.872 & 0.977 \\
\hline 18 & 1.028 & 1.000 & 1.019 & 0.917 & 0.950 & 0.826 & 0.969 \\
\hline 19 & 1.025 & 0.996 & 1.015 & 0.917 & 0.948 & 0.828 & 0.955 \\
\hline 20 & 1.029 & 1.001 & 1.020 & 0.926 & 0.956 & 0.843 & 0.959 \\
\hline 21 & 1.032 & 1.003 & 1.022 & 0.938 & 0.964 & 0.862 & 0.952 \\
\hline 22 & 1.033 & 1.003 & 1.023 & 0.938 & 0.964 & 0.862 & 0.953 \\
\hline 23 & 1.027 & 0.999 & 1.018 & 0.914 & 0.947 & 0.822 & 0.965 \\
\hline 24 & 1.022 & 0.989 & 1.010 & 0.913 & 0.942 & 0.824 & 0.930 \\
\hline 25 & 1.019 & 0.983 & 1.008 & 0.916 & 0.943 & 0.834 & 0.913 \\
\hline 26 & 1.001 & 0.961 & 0.986 & 0.886 & 0.914 & 0.790 & 0.872 \\
\hline 27 & 1.026 & 0.990 & 1.017 & 0.933 & 0.958 & 0.863 & 0.922 \\
\hline 28 & 1.011 & 0.980 & 1.009 & 0.947 & 0.968 & 0.920 & 0.941 \\
\hline 29 & 1.006 & 0.965 & 0.993 & 0.899 & 0.925 & 0.811 & 0.874 \\
\hline 30 & 0.995 & 0.950 & 0.979 & 0.879 & 0.906 & 0.781 & 0.847 \\
\hline
\end{tabular}

Multiple Contingency Analysis for optimal placement and estimate the value of SVC for power loss reduction employing Genetic Algorithm.

\section{CONCLUSION}

In this paper, the GA is evaluated to find ideal position and value of SVC to reduce loss and enhance the voltage profile. For different cases of increased load demand and generation loss at bus $13, \mathrm{SVC}$ is utilized to analyze voltage profile and loss of system. The suggested method is executed on IEEE 30 bus system to calculate ideal position and value of the SVC. For higher loading (100\% increase in loading) and removal of generator it is observed that around $5.822 \mathrm{MW}$ power loss is reduced. It is observed that voltage profile at bus number 26 is improved from 0.790 p.u to $0.872 \mathrm{p} . \mathrm{u}$ and at bus number 30 is improved from 0.781 p.u to 0.847 p.u. GA is executed successfully and SVC value at ideal position is acquired for different cases. For practical power system it can also be employed. 


\section{REFERENCES}

[1] Saravanan M.,Slochanal S.M. R., Venkatesh P., Prince Stephen Abraham J., "Application of article swarm optimization technique for optimal location of FACTS devices considering cost of installation and system loadability", Electric Power System Research, Vol 77, pp. 276-283, 2007.

[2] Singh J.G., Singh S. N., Srivastava S. C, "An Approach for Optimal Placement of Static V AR Compensators Based on Reactive Power Spot Price", IEEE Trans. Power Syst, Vol 22,No.4, pp. 2021-2029,2007.

[3] Thukaram D., Lomi A., Selection of static VAR compensator location and size for system voltage stability improvement,Electr Power Syst Res, 54 (2000): 139-150.

[4] Mithulananthan N., Cañizares C. A., Reeve J., Comparison of PSS, SVC and STATCOM controllers for damping power system oscillation, IEEE Trans Power Syst, 18 (2003),786-792.

[5] D. E. Goldberg, Genetic algorithms in search, optimization, and machine learning. New York: Addison-Wesley, 1989.

[6] Hadi Saadat, Power System Analysis, Tata McGRAW- HILL Edition.

[7] Neelanbar Singh Chouhan, N.V. Srikanth, B. Vijay Kumar, Optimal placement of SVC to minimize loss and improve the voltage profile under power system contingency using GA, Proceedings of 5th SARC-IRF International Conference, 25th May-2014.

[8] J.W. Nims a, A.A. El-Keib b, R.E. Smith c, Contingency ranking for voltage stability using a genetic algorithm, Electric Power Systems Research 43 (1997) 69-76.

[9] J. Zhu, G. Xu, Approach to automatic contingency selection by reactive type performance index, IEE Proc. C 138 (1) (1991) 65568.

[10] [G. Jasmon, L. Lee, New contingency ranking technique incorporating a voltage stability criterion, IEE Proc. C 140 (4) (1993) 87-90.

[11] A. Mohamed. G. Jasmon, Voltage contingency selection technique for security assessment. IEE Proc. C 136 (1) (1989) 24428.

[12] S. Singh, P. Kalra, S. Srivastava, Novel non-iterative load flow for voltage contingency analysis, Electr. Power Energy Syst. 16 (1) (1994) 11-16. 